\title{
Preweaned heifer management on US dairy operations: Part III. Factors associated with Cryptosporidium and Giardia in preweaned dairy heifer calves
}

\author{
N. J. Urie, ${ }^{\star} \dagger$ J. E. Lombard, $\dagger^{1}$ C. B. Shivley, $\uparrow \ddagger$ A. E. Adams,$\dagger \ddagger^{2}$ C. A. Kopral, $\dagger$ and M. Santin§ \\ ${ }^{*}$ Department of Clinical Sciences, College of Veterinary Medicine and Biomedical Sciences, Colorado State University, Fort Collins 80523-1678 \\ tUSDA-Animal and Plant Health Inspection Service (APHIS)-Veterinary Services (VS) Center for Epidemiology and Animal Health, \\ National Animal Health Monitoring System, Fort Collins, CO 80526-8117 \\ †Department of Animal Sciences, College of Agricultural Sciences, Colorado State University, Fort Collins 80523-1171 \\ $\S$ Environmental Microbial and Food Safety Laboratory, USDA-Agricultural Research Service, Beltsville, MD 20705
}

\begin{abstract}
The objective of this study was to evaluate management practices and environmental factors associated with cryptosporidiosis and giardiasis in preweaned heifer calves on US dairy operations. This study was conducted as part of the calf component of the National Animal Health Monitoring System's Dairy 2014 study. The calf component included 104 dairy operations in 13 states and was an 18-mo longitudinal study focused on dairy heifer calves from birth to weaning. Fecal samples were collected from 2,249 calves: 839 calves in the West region (California, Colorado, and Washington) and 1,410 calves in the East region (Iowa, Michigan, Minnesota, Missouri, New York, Ohio, Pennsylvania, Vermont, Virginia, and Wisconsin). Fecal samples were collected only once from calves during the preweaning period. Samples were collected from calves 3 to $66 \mathrm{~d}$ of age, with a mean of 22 d. Overall, Cryptosporidium and Giardia were detected in 43.1 and $30.5 \%$ of fecal samples, respectively. Backward elimination logistic model selection was used after univariate screening to determine which management practices and environmental factors significantly affected the presence of Cryptosporidium or Giardia. The final Cryptosporidium model included herd size, days of age at fecal collection, and average temperature-humidity index for the month of fecal collection (fTHI). Cryptosporidium was found on a higher percentage of large operations $(\geq 500$ cows) than small operations (30 to 99 cows). Younger calves were more likely to have a fecal sample positive for Cryptosporidium than samples from older calves.
\end{abstract}

Received October 27, 2017.

Accepted April 22, 2018.

${ }^{1}$ Corresponding author: Jason.E.Lombard@aphis.usda.gov

${ }^{2}$ Current affiliation: School of Agriculture and Natural Resources, Morrisville State College, Morrisville, NY 13408.
Fecal samples from calves during the warmer parts of the year (fTHI >70) were more likely to be positive for Cryptosporidium than samples collected in colder months (fTHI <20). The final Giardia model included herd size, days of age at fecal collection, average fTHI, failure of passive transfer status, and average daily gain $(\mathrm{kg} / \mathrm{d})$ during the preweaning period. Giardia was isolated more frequently from calves on small operations than on large operations and from calves that were older compared with younger calves. Giardia was more frequently isolated in warmer months. Samples from calves with failure of passive transfer were more likely to have Giardia than calves with adequate passive transfer (>10 g/L IgG). Average daily gain during the preweaning period was lower in calves from which Giardia was isolated. These results highlight the factors associated with the presence of Cryptosporidium and Giardia in preweaned dairy heifer calves.

Key words: dairy heifer calves, Cryptosporidium, Giardia

\section{INTRODUCTION}

Cryptosporidium parvum and Giardia duodenalis are intestinal protozoa that are commonly found in calves and have the potential to cause diarrhea (Huetink et al., 2001). Cryptosporidium causes diarrhea via destruction of the small intestinal epithelium. Epithelial destruction results in villus atrophy, crypt hyperplasia, and cell death, which lead to impaired nutrient digestion and transport (Di Genova and Tonelli, 2016). Cryptosporidium in endemic herds has morbidity rates that may reach $100 \%$; however, mortality is infrequently observed (de Graaf et al., 1999). Giardia causes diarrhea via diffuse shortening of the brush border microvilli and decreased activity of the small intestinal brush border enzymes, specifically lipase. The microvillus shortening leads to a decrease in absorptive capacity of the 
small intestine. The combined effects of decreased resorption and brush border enzyme deficiencies results in malabsorptive diarrhea and decreased weight gain (Olson, 2004). Currently, there are no licensed drugs in the United States available to treat Cryptosporidium or Giardia in ruminants. Supportive therapy, including fluids and electrolytes, is recommended for calves with Cryptosporidium- or Giardia-induced diarrhea (Thompson et al., 2008). Additionally, because infection of both protozoans occurs via the fecal-oral route (directly via the ingestion of feces or indirectly via ingestion of contaminated food or water), good husbandry, including the removal of feces from calf environments, will help minimize re-infection and transmission of Cryptosporidium and Giardia (Thompson et al., 2008).

Infections with Cryptosporidium and Giardia are of public health concern because some of their species and assemblages are zoonotic. For Cryptosporidium, molecular studies of cryptosporidiosis in cattle have shown that 4 species are mainly responsible for most cattle infections: C. parvum, C. bovis, C. ryanae, and $C$. andersoni (Santín, 2013). The host age-related susceptibility to these species has been described previously; virtually all infections in calves 8 wk of age and younger are caused by C. parvum (Santín et al., 2004; Fayer et al., 2006, 2007; Langkjær et al., 2007; Thompson et al., 2007). Cryptosporidium parvum is known to infect humans worldwide and is recognized as the major zoonotic Cryptosporidium species.

Molecular characterization of $G$. duodenalis has revealed 8 major assemblages with different host ranges, with only assemblages $\mathrm{A}$ and $\mathrm{B}$ identified in humans (Feng and Xiao, 2011), although both assemblages A and $\mathrm{B}$ have been identified in a wide range of other mammalian hosts (Monis et al., 2003; Thompson and Monis, 2004). In cattle, 3 assemblages have been commonly detected: A, B, and E, with $\mathrm{E}$ being most frequently reported, followed by A (Trout et al., 2004, Langkjær et al., 2007; Geurden et al., 2008; Santín et al., 2008). Thus, calves should be considered a potential source of human infections.

The objectives of this prospective, longitudinal study were to examine management and environmental associations for Cryptosporidium and Giardia detection in preweaned dairy heifers.

\section{MATERIALS AND METHODS}

\section{Study Design}

The USDA's National Animal Health Monitoring System (NAHMS) conducts national surveys to collect information on the health, management, and productivity of domestic livestock species (USDA, 2016).
In 2014, a nationwide survey was conducted to collect information about the US dairy industry and included an 18-mo longitudinal preweaned heifer calf study, which included a cross-sectional study to evaluate the presence of Cryptosporidium and Giardia.

The calf component was part of the NAHMS's Dairy 2014 study, and consisted of a convenience sample of 104 dairy operations. These operations were located in 13 states, including California, Colorado, and Washington in the West region, and Iowa, Michigan, Minnesota, Missouri, New York, Ohio, Pennsylvania, Vermont, Virginia, and Wisconsin in the East region. Dairy operations were categorized based on the number of mature cows, as small (30 to 99 cows), medium (100 to 499 cows), and large ( $\geq 500$ cows). Figures describing the study sample and operations can be found in Urie et al. (2018).

Data collection for the calf component of the study occurred from March 2014 through September 2015. Each operation was instructed to enroll 24 heifer calves over a 1-yr period, or an average of 2 calves/mo. Farm personnel selected which calves to enroll in the study; however, a calf must have been alive at $24 \mathrm{~h}$ of age to be enrolled. Because fewer operations participated than originally planned, the target number enrolled per operation was increased to 48 calves. Additionally, because enrollment of farms did not occur as quickly as anticipated, the study encompassed 18 mo instead of the 12-mo period that was planned.

\section{Heifer Calf Health Card}

Each calf enrolled in the study had a Heifer Calf Health Card ("Calf Card") filled out to record information on events that occurred from birth to weaning (https://www.aphis.usda.gov/animal_health/nahms/ dairy/downloads/dairy14ques/CalfHealth.pdf). The Calf Card contained questions in both English and Spanish and was filled out by farm personnel, a veterinary medical officer, extension personnel, veterinarians, or a combination of people involved with calf raising. The Calf Card included birth data (e.g., birth date, weight, and calving ease), colostrum feeding data (including timing, amount, and method of colostrum feeding), preweaning housing and procedures data (e.g., housing, ventilation, bedding, navel disinfection, and dehorning), milk feeding (including type of liquid diet fed, any additives, and method of feeding), milk consumption record (volume and frequency of feedings), preweaning growth record (hip height and heart girth recordings every $2 \mathrm{wk}$ ), biologic sampling record (including serum collection and fecal sampling dates), vaccinations, disease incidence and treatment, weaning data (weaning date, primary weaning criteria), and any 
additional notes. Starter feed labels and milk replacer labels, if applicable, were also collected.

Producers were provided with the Calf Health Scoring Chart (https://www.vetmed.wisc.edu/dms/fapm/ apps/chs.htm) to guide the reporting of clinical signs. The goal of the study was to collect recognized clinical signs and causes of death, not to standardize clinical signs and causes of death across operations. All clinical signs and causes of death were reviewed, edited, and categorized, as described in the statistical analysis section.

Due to the variation observed in the quantity and quality of the liquid diet fed per day, kilograms of protein and fat fed per day were calculated for each calf. Information regarding the amount of liquid diet fed per feeding and the frequency of feedings per day were recorded on the Calf Card and used to calculate the total amount of liquid diet fed. For calves fed milk replacer, the percent protein and percent fat were obtained from the producer-reported values or the milk replacer label. For calves fed whole or waste milk, percent protein was set at $3.1 \%$ and percent fat as $3.8 \%$ (as-fed basis; Chester-Jones and Hoffman, 2003). The total amounts of protein and fat were calculated and then divided by the number of days fed a liquid diet to determine the average kilograms of protein and fat fed per day in the liquid diet.

Additives in the liquid diet were categorized as antibiotics, direct-fed microbials, fly control, acids/preservatives, coccidiostats, vitamins and minerals, or other additives. Information regarding calf starter included the percent protein and the age that starter was first offered; starter intake was not recorded.

\section{Biological Sampling}

Before enrollment in the study, calves were screened for persistent infection with bovine viral diarrhea virus (BVDV). V-Cut ear notchers (Nasco, Fort Atkinson, WI) were used to collect ear notch samples from all calves, which were tested on-farm for BVDV using the Idexx SNAP BVDV Antigen Test (Idexx, Westbrook, $\mathrm{ME})$. Calves that tested positive for BVDV were excluded from the study. Colostrum samples (40-50 mL) from the first feeding of colostrum administered to each calf were collected in conical screw-top tubes by farm personnel and frozen until shipping. Blood samples (5 $\mathrm{mL}$ ) from calves between 1 and $7 \mathrm{~d}$ of age were collected in serum separator tubes by veterinary medical officers or animal health technicians, and samples were centrifuged if possible before shipping. Colostrum and blood samples were shipped together on ice to USDA's National Veterinary Services Laboratories (Ames, IA). Blood samples were centrifuged at the National Veteri- nary Services Laboratories and serum was separated. Serum and colostrum samples were then accumulated and shipped in bulk to the Saskatoon Colostrum Co. (Saskatoon, SK, Canada) for testing. Colostrum samples were tested for IgG concentration using radial immunodiffusion and Brix score using a digital Brix refractometer. Serum samples were tested for IgG concentration using radial immunodiffusion, total protein, and Brix score using a digital Brix refractometer. Blood samples collected within $24 \mathrm{~h}$ of birth or after $7 \mathrm{~d}$ of age were excluded from this analysis. A complete description of the methods used for Brix scoring and IgG determination can be found in Urie et al. (2018).

For evaluation of enteric parasites, veterinary medical officers or animal health technicians collected approximately $50 \mathrm{~g}$ of feces directly from the rectum of each calf between 2 and 4 wk of age. Fecal samples were placed in cylindrical screw-top containers and shipped on ice to the USDA Agricultural Research Service's Environmental Microbial Food Safety Laboratory (Beltsville, MD) as soon as possible after sample collection. Fecal samples were tested by immunofluorescence microscopy for Cryptosporidium parvum and Giardia duodenalis.

Cryptosporidium oocysts and Giardia cysts were concentrated from feces as previously described (Fayer et al., 2000; Santín et al., 2004). Briefly, $15 \mathrm{~g}$ of feces from each specimen cup was mixed with $35 \mathrm{~mL}$ of distilled water $\left(\mathbf{d H}_{\mathbf{2}} \mathbf{O}\right)$. The suspension was passed through a sieve with a $45-\mu \mathrm{m}$ pore size screen. The filtrate volume was adjusted to $50 \mathrm{~mL}$ with $\mathrm{dH}_{2} \mathrm{O}$ and centrifuged at $1,800 \times g$ for $15 \mathrm{~min}$. The pellet was resuspended in a mixture of $25 \mathrm{~mL}$ of $\mathrm{dH}_{2} \mathrm{O}$ and $25 \mathrm{~mL}$ of $\mathrm{CsCl}(1.4 \mathrm{~g} / \mathrm{L})$ and centrifuged at $300 \times g$ for $20 \mathrm{~min}$. Supernatant (4 $\mathrm{mL}$ ), aspirated from each suspension, was washed with $\mathrm{dH}_{2} \mathrm{O}$ and the final pellet was examined by microscopy as described below.

A $2-\mu \mathrm{L}$ suspension of the pellet was transferred to a well (11-mm diameter) of a 3 -well glass microscope slide, and $2 \mu \mathrm{L}$ of premixed Merifluor reagent (Meridian Diagnostics, Cincinnati, $\mathrm{OH}$ ) was added. The slide was covered with a $24 \mathrm{~mm} \times 50 \mathrm{~mm}$ coverslip and the entire well area was examined and oocysts/cysts counted by fluorescence microscopy at $400 \times$ using Zeiss Axioskop fluorescence microscope (Zeiss, Oberkochen, Germany) equipped with epifluorescence and a fluorescein isothiocyanate (FITC)-Texas Red dual wavelength filter.

\section{Growth Measurements}

Calves were measured approximately every 2 wk during the preweaning period to measure growth. Height/ weight tapes from Coburn (Nasco, Fort Atkinson, WI) were provided for measuring calves. For consistency, 
it was recommended that 1 trained veterinary medical officer or animal health technician complete the measurements on all calves enrolled on an operation. Birth weights were estimated using a scale, hoof circumference, or heart girth circumference and reported in pounds or kilograms. The methods that operations used to estimate birth weight were not captured. Hip height and heart girth circumference were measured approximately every $2 \mathrm{wk}$ and recorded in centimeters. Heart girth circumference in centimeters was converted to kilograms using the following equation (Heinrichs et al., 1992):

$$
\begin{aligned}
& \mathrm{BW}(\mathrm{kg})=\left[\left(0.02655 \times \mathrm{cm}^{2}\right)\right. \\
& +(-2.876 \times \mathrm{cm})+102.71]
\end{aligned}
$$

Preweaning weight gain was calculated by subtracting the birth weight from the final weight. Average daily gain was calculated by taking the weight gain during the preweaning period divided by the number of days between birth weight and final weight (approximately the preweaning period). Final weights did not always occur at the same time as weaning. However, only calves with final weight measurements within $14 \mathrm{~d}$ of weaning were included in the analysis.

\section{Environmental Factors}

Temperature-humidity index (THI) data were obtained monthly by county from the National Oceanic and Atmospheric Administration (NOAA, 2016). The THI accounts for the effects of temperature and relative humidity, and the equation uses the dry bulb temperature $\left(\mathrm{T},{ }^{\circ} \mathrm{F}\right)$ and relative humidity $(\mathrm{RH})$. The equation used for this analysis was THI $=\mathrm{T}-[0.55-(0.55 \times$ $\mathrm{RH} / 100)] \times(\mathrm{T}-58)$. Each calf was assigned a THI for the month of fecal collection (fTHI).

\section{Statistical Analysis}

When each calf was weaned, the Calf Card was mailed to USDA NAHMS (Fort Collins, CO). Initial ongoing validation was performed on every Calf Card as it came in, followed by data entry into SAS (version 9.4; SAS Institute Inc., Cary, NC). Once all Calf Cards were entered, the data were validated again by NAHMS staff and merged with the results from the colostrum, serum, and fecal testing obtained from the laboratories. Descriptive data were analyzed using the FREQUENCY and MEANS procedures for categorical and continuous variables, respectively.

Logistic regression models were constructed to determine the factors associated with Cryptosporidium and
Giardia detection. Operation was included in the model as a random variable to account for clustering of calves within operation. Predictor variables were considered for the models based on biological plausibility. The outcome was the presence or absence of protozoa oocysts / cysts, and, to be included in the analysis, calves had to have data for all of the variables initially included in the model. Variables were tested for potential confounding using variance inflation factors. Continuous variables were tested for linearity and if they were not linear, they were categorized and evaluated as categorical variables. For both Cryptosporidium and Giardia model building, univariate screening was used. Variables with $P<0.20$ were considered for inclusion in the initial multivariable model. Stepwise backward elimination model selection in PROC GENMOD was used to construct the final model, with $P<0.05$ considered significant and thus included in the model.

\section{RESULTS}

\section{Descriptive Summary}

Fecal samples were obtained from 2,249 calves, with the majority $(89.2 \%)$ of calves being Holstein. Samples were collected from all herd sizes with large operations being over-represented (314, 611, and 1,324; calves on small, medium, and large operations, respectively). The age at fecal sample collection for each calf ranged from 3 to $66 \mathrm{~d}$, with an average age of $22 \mathrm{~d}$. Sample collection occurred throughout the year, starting on April 12, 2014, and ending on July 23, 2015. Cryptosporidium was detected in $43.1 \%$ of preweaned heifer calves and Giardia was detected in $30.5 \%$ of preweaned heifer calves. Of all tested calves, $13.3 \%$ had a positive result for both Cryptosporidium and Giardia. Therefore, $39.8 \%$ of calves tested were negative for both Cryptosporidium and Giardia (Figure 1).

The percentage of samples that tested positive changed based on the age at fecal sample collection. Cryptosporidium was more prevalent in young calves, with $63.3 \%$ of calves less than 2 wk of age testing positive compared with only $9.1 \%$ of calves greater than 6 wk of age testing positive. Giardia was more prevalent in older calves, with $36.4 \%$ of calves greater than $6 \mathrm{wk}$ of age testing positive and only $16.7 \%$ of calves less than 2 wk of age testing positive (Figure 2). Before model building, variables that were thought to affect the presence of Cryptosporidium and Giardia were analyzed univariately. More Cryptosporidium-positive specimens were detected in the West region $(48.9 \%)$ than in the East region (40.5\%). In contrast, more Giardia-positive specimens were detected in the East region (33.6\%) than in the West region (25.2\%; Figure 3). On large 


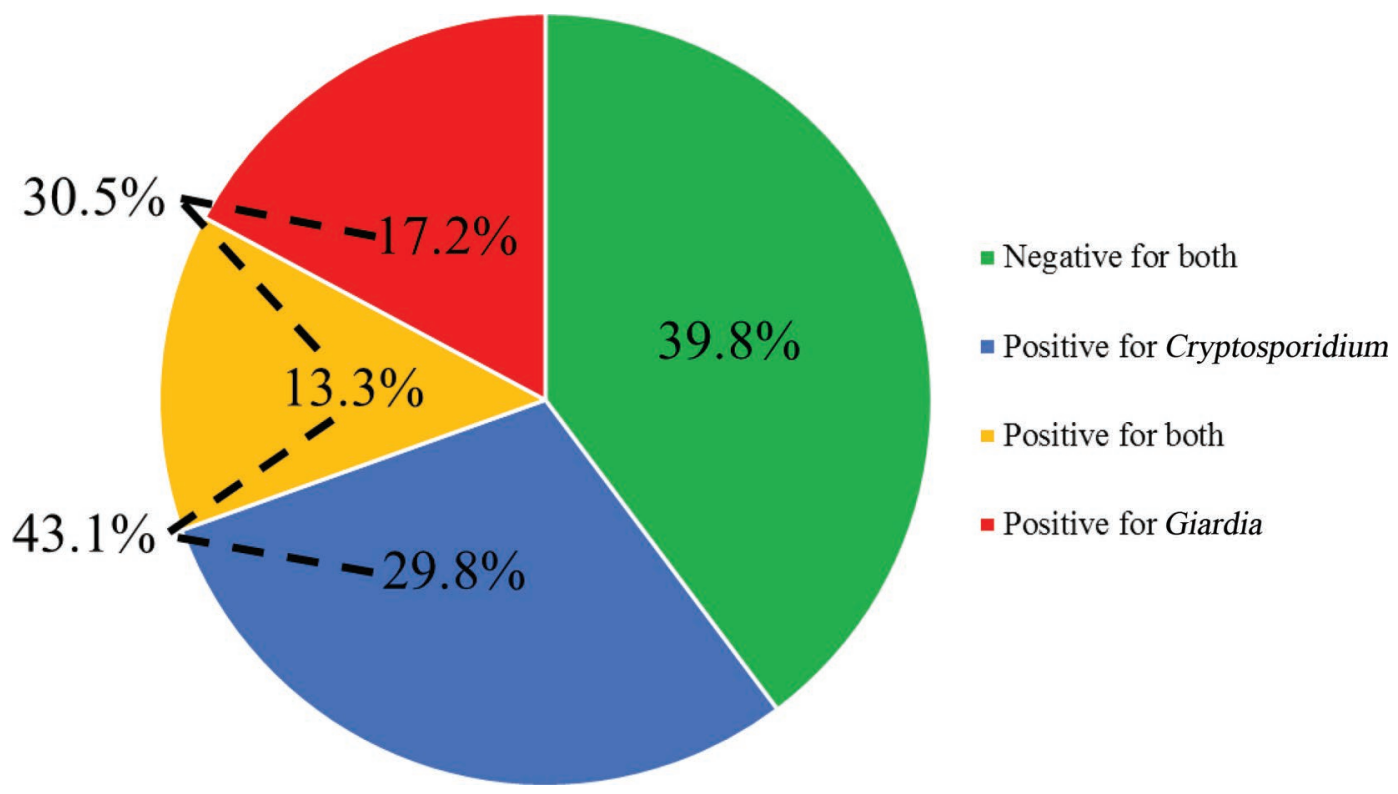

Figure 1. Percentage of preweaned heifer calves testing positive for Cryptosporidium and Giardia. The total percentage of calves with a positive Cryptosporidium result and the total percentage of calves with a positive Giardia result are represented by dashed lines. Color version available online.

operations, $47.8 \%$ of specimens were Cryptosporidiumpositive compared with $37.6 \%$ on both medium and small operations. Conversely, the prevalence of Giardia was highest on small operations (43.3\%) compared with medium and large operations (34.0 and 25.8\%, respectively; Figure 4). During the month of October, $54.6 \%$ of calves excreted Cryptosporidium, whereas during March, 35.9\% of calves excreted Cryptosporidium. Giardia followed a similar trend, with the highest number of positive calves in November $(41.7 \%)$ and the lowest in February (17.2\%; Figure 5).

\section{Cryptosporidium Model}

Of the 2,249 calves with submitted fecal samples, 1,824 had complete data and were included in the inferential modeling for Cryptosporidium. Initial variables included in the multivariable model after univariable

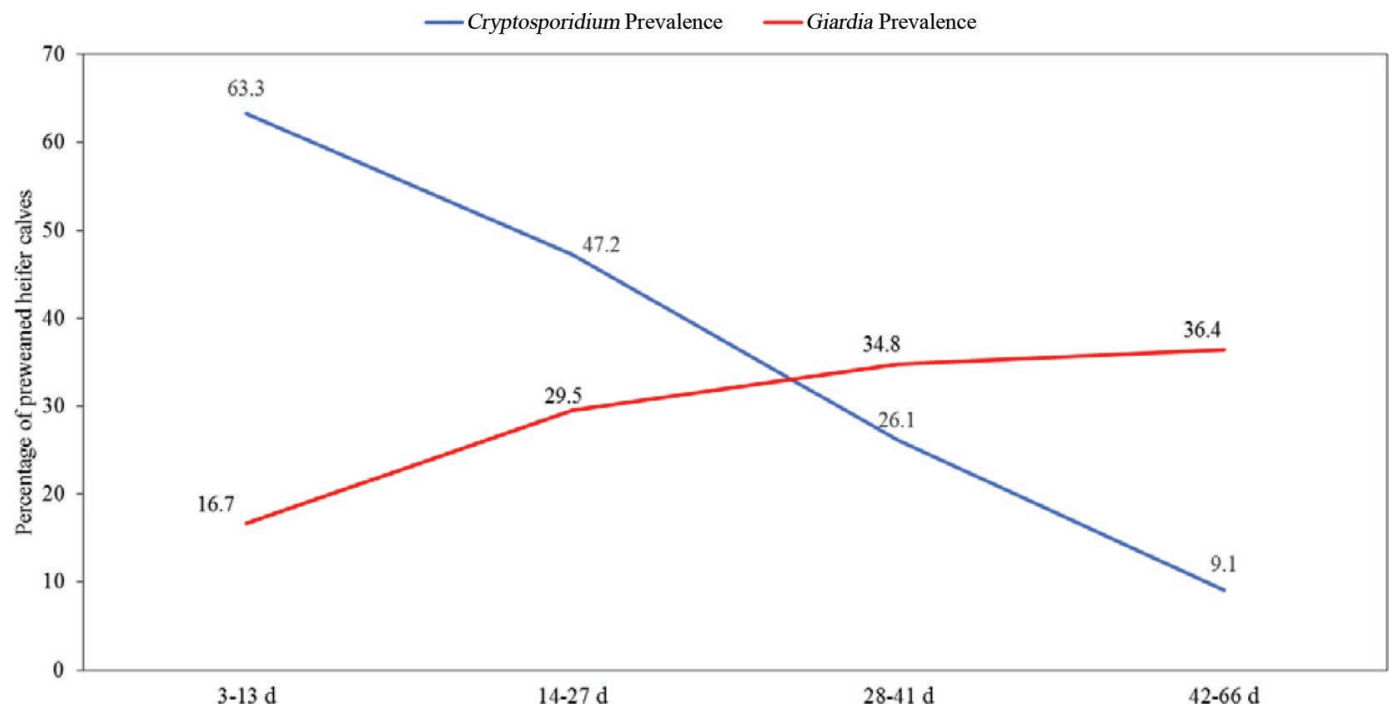

Figure 2. Percentage of preweaned heifer calves that tested positive for Cryptosporidium and Giardia by age of calf (in days) at fecal collection. Color version available online. 


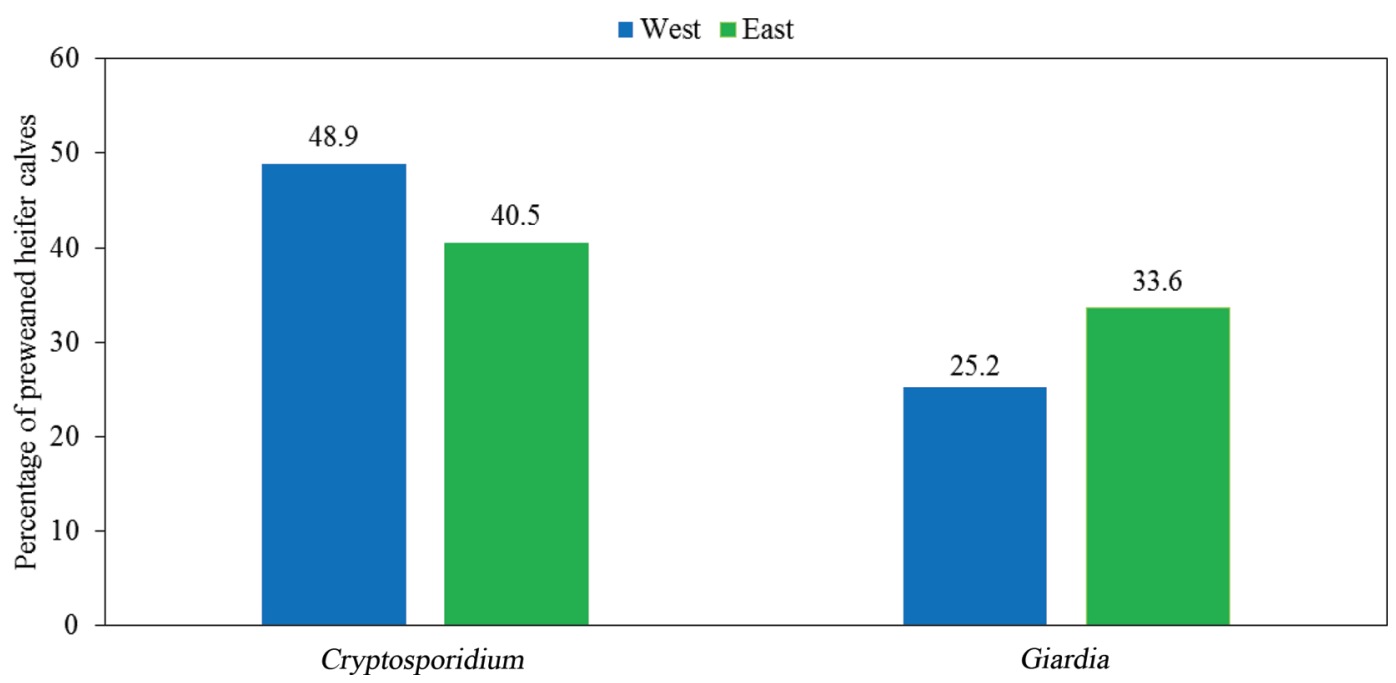

Figure 3. Percentage of preweaned heifer calves that tested positive for Cryptosporidium and Giardia by region. West region $=$ California, Colorado, Washington; East region = Iowa, Michigan, Minnesota, Missouri, New York, Ohio, Pennsylvania, Vermont, Virginia, and Wisconsin. Color version available online.

screening for Cryptosporidium included operation as a random effect to account for clustering of calves within farm, region, herd size, dam lactation, navel disinfection, failure of passive transfer, housing ventilation, bedding type, days of age at fecal collection, fTHI, and ADG (Tables 1 and 2). The final multivariable model for Cryptosporidium in calves included herd size $(P=$ $0.024)$, days of age at fecal collection $(P<0.001)$, and fTHI $(P<0.001$ (Table 3$)$.

Large operations had a higher percentage of calves with Cryptosporidium ( $46.8 \%$ of calves with a positive fecal result), whereas small and medium-sized operations saw no difference in the number of Cryptosporidium positive calves (37.7 and $37.6 \%$, respectively). Thus, when compared with small operations, large operations had an odds ratio (OR) of 1.55. The variance inflation factors with and without region in the model were 1.324 and 1.022, respectively. Given this small difference, region was not forced into the model. After holding other independent variables in the model constant, younger calves at the time of fecal collection had a higher risk of a positive Cryptosporidium result than older calves at

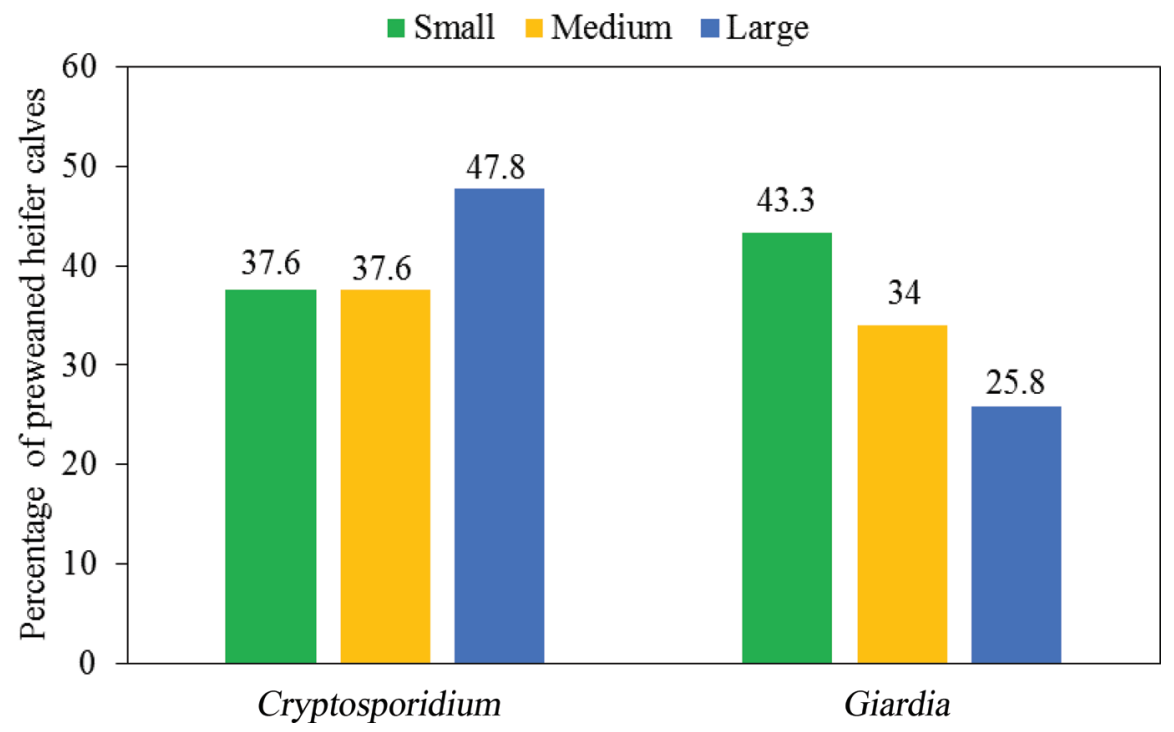

Figure 4. Percentage of preweaned heifer calves that tested positive for Cryptosporidium and Giardia by herd size. Small = 30-99; Medium $=100-499 ;$ Large $=\geq 500$. Color version available online. 


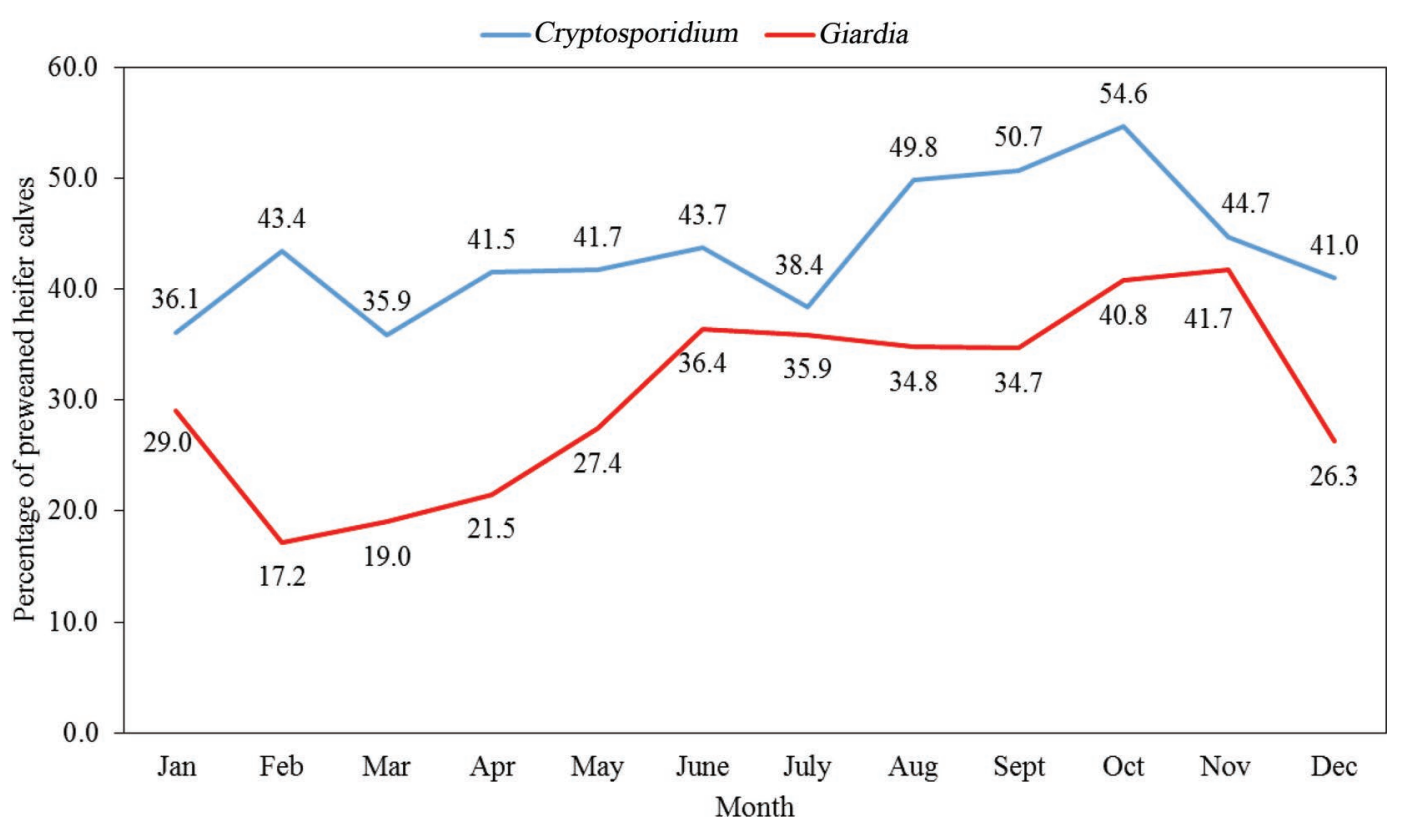

Figure 5. Percentage of preweaned heifer calves that tested positive for Cryptosporidium and Giardia by month. Color version available online.

fecal collection $(\mathrm{OR}=0.91$; Figure $6 \mathrm{a})$. To demonstrate the risk of Cryptosporidium with this continuous variable, 2 different ages at fecal collection were selected. A calf at $14 \mathrm{~d}$ of age had a predicted Cryptosporidium risk of $56.5 \%$, whereas a calf at $35 \mathrm{~d}$ of age had a predicted Cryptosporidium risk of $16.7 \%$. Similarly, an increase in average THI for the month of fecal collection was associated with an increase of detection of Cryptosporidium in the fecal sample (OR $=1.01$; Figure $6 \mathrm{~b})$. Two extreme fTHI points were selected to demonstrate the predicted risk of this continuous variable. An fTHI of 20, below the reported calf thermoneutral zone, had a predicted Cryptosporidium risk of $32.0 \%$, whereas an fTHI of 70, above the reported calf thermoneutral zone, had a predicted Cryptosporidium risk of $45.7 \%$.

\section{Giardia Model}

Of the 2,249 calves with submitted fecal samples, 1,785 calves had complete data and were included in the inferential modeling for Giardia. Initial variables considered for the multivariable model after univariate screening for Giardia included region, herd size, calving event attendance, navel disinfection, failure of passive transfer, sex of the primary caretaker, any antibiotics in the liquid diet, any additives in the liquid diet, days of age at fecal collection, fTHI, protein per day $(\mathrm{kg} / \mathrm{d})$, and ADG (Tables 1 and 4). The final multivariable model for Giardia detection in calves included herd size $(P=0.006)$, days of age at fecal collection $(P=$ $0.003)$, fTHI $(P<0.001)$, failure of passive transfer status where serum $\operatorname{IgG}$ was $<10 \mathrm{~g} / \mathrm{L}(P=0.037)$, and ADG $(\mathrm{kg} / \mathrm{d})$ during the preweaning period $(P=0.021$; Table 5).

A smaller herd size was correlated with a positive Giardia result. Calves on small operations had a $43.3 \%$ prevalence of Giardia; medium operations had a $34.0 \%$ prevalence; and large operations had a $25.8 \%$ prevalence. Thus, when compared with large operations, medium operations had an OR of 1.50 and small operations had an OR of 2.30. After holding other independent variables in the model constant, calves that were older at the time of fecal collection had a higher risk of a positive Giardia result than younger calves at the time of fecal collection $(\mathrm{OR}=1.04$; Figure $6 \mathrm{c})$. To demonstrate the risk of Giardia with this continuous variable, 2 different ages at fecal collection were selected. A calf $14 \mathrm{~d}$ of age at fecal collection resulted in a predicted Giardia risk of $28.3 \%$ and a calf $35 \mathrm{~d}$ of age at fecal collection had a predicted Giardia risk of $44.7 \%$. Similarly, an increase in fTHI was directly correlated with an increase in detection of Giardia in the fecal sample ( $\mathrm{OR}=1.02$; Figure $6 \mathrm{~d})$. For example, an fTHI of 20, selected to represent cold months, had a Giardia risk of $24.5 \%$, whereas an fTHI of 70 , representing hot months, had a Giardia risk of $41.1 \%$. Failure of passive transfer status (serum $\operatorname{IgG}<10 \mathrm{~g} / \mathrm{L}$ ) was directly correlated with a positive Giardia fecal sample. A calf 


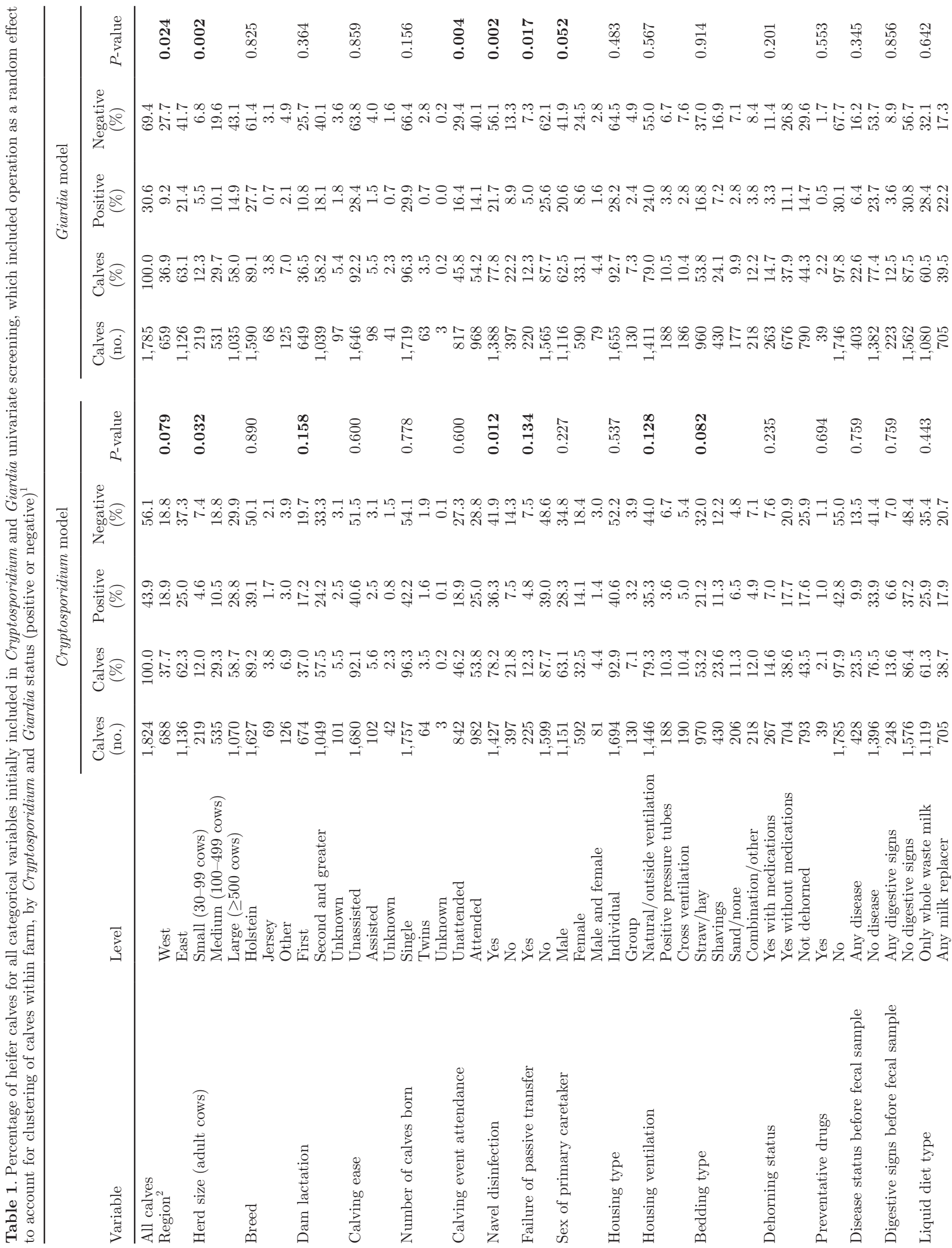




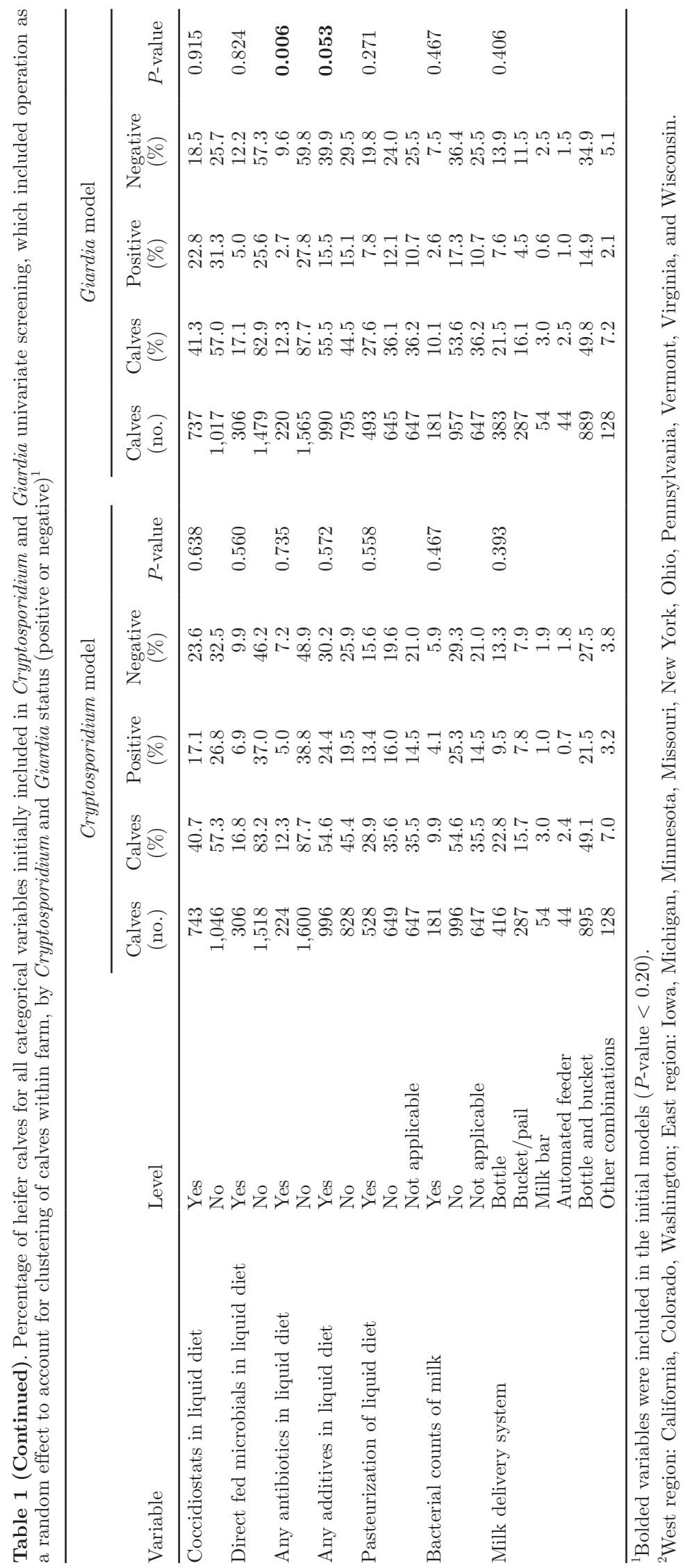


URIE ET AL.
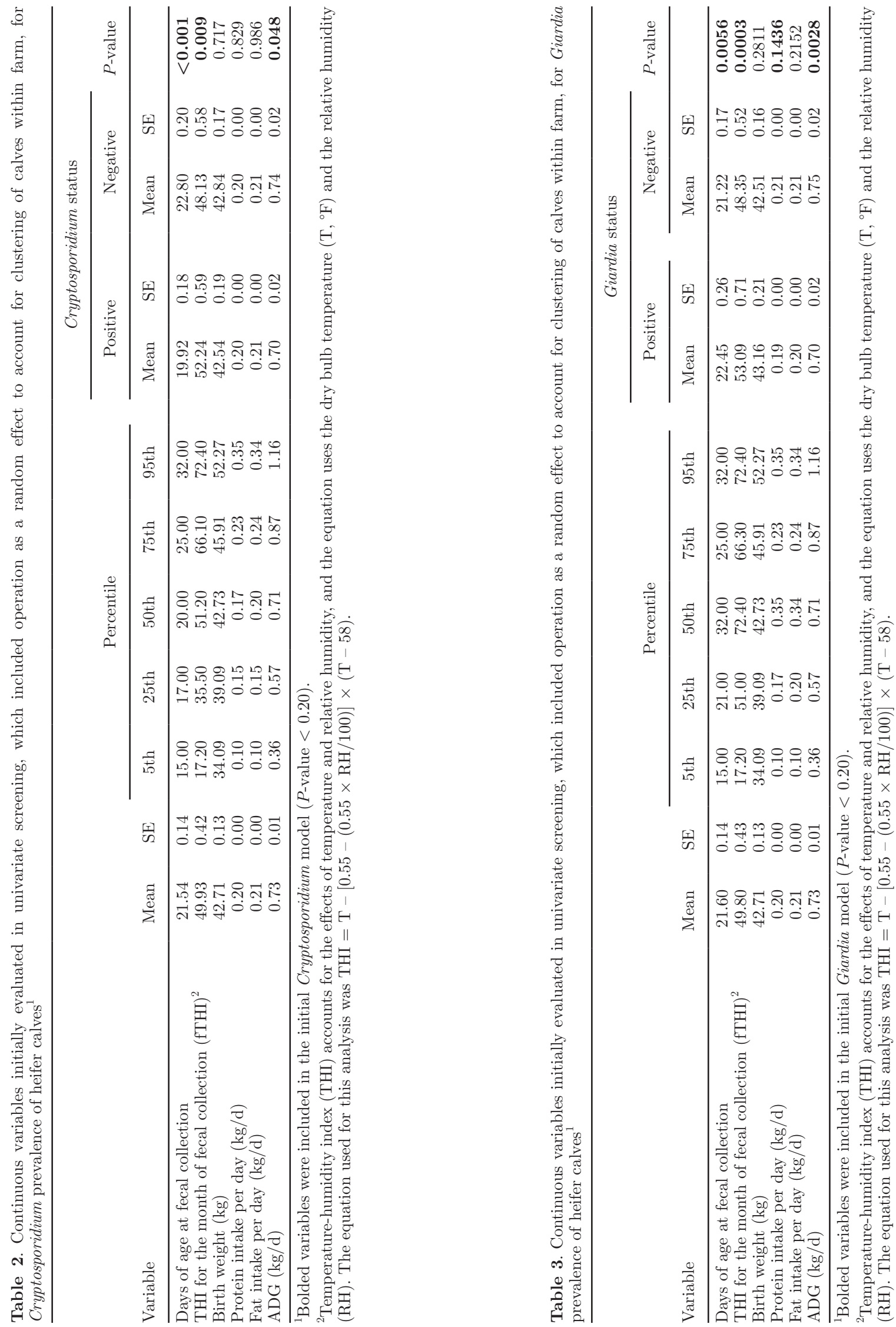
that had failure of passive transfer was 1.34 times more likely to have a positive Giardia fecal sample than a calf with adequate passive transfer. Additionally, ADG $(\mathrm{kg} / \mathrm{d})$ was inversely correlated with the detection of Giardia (OR $=0.71$; Figure 6e). Two points, to represent low and adequate ADG, were selected for this continuous variable to illustrate the risk of Giardia. A calf with an ADG of $0.45 \mathrm{~kg} / \mathrm{d}$ resulted in a predicted Giardia risk of $38.7 \%$, whereas a calf with an ADG of $1.1 \mathrm{~kg} / \mathrm{d}$ resulted in a predicted Giardia risk of $27.2 \%$.
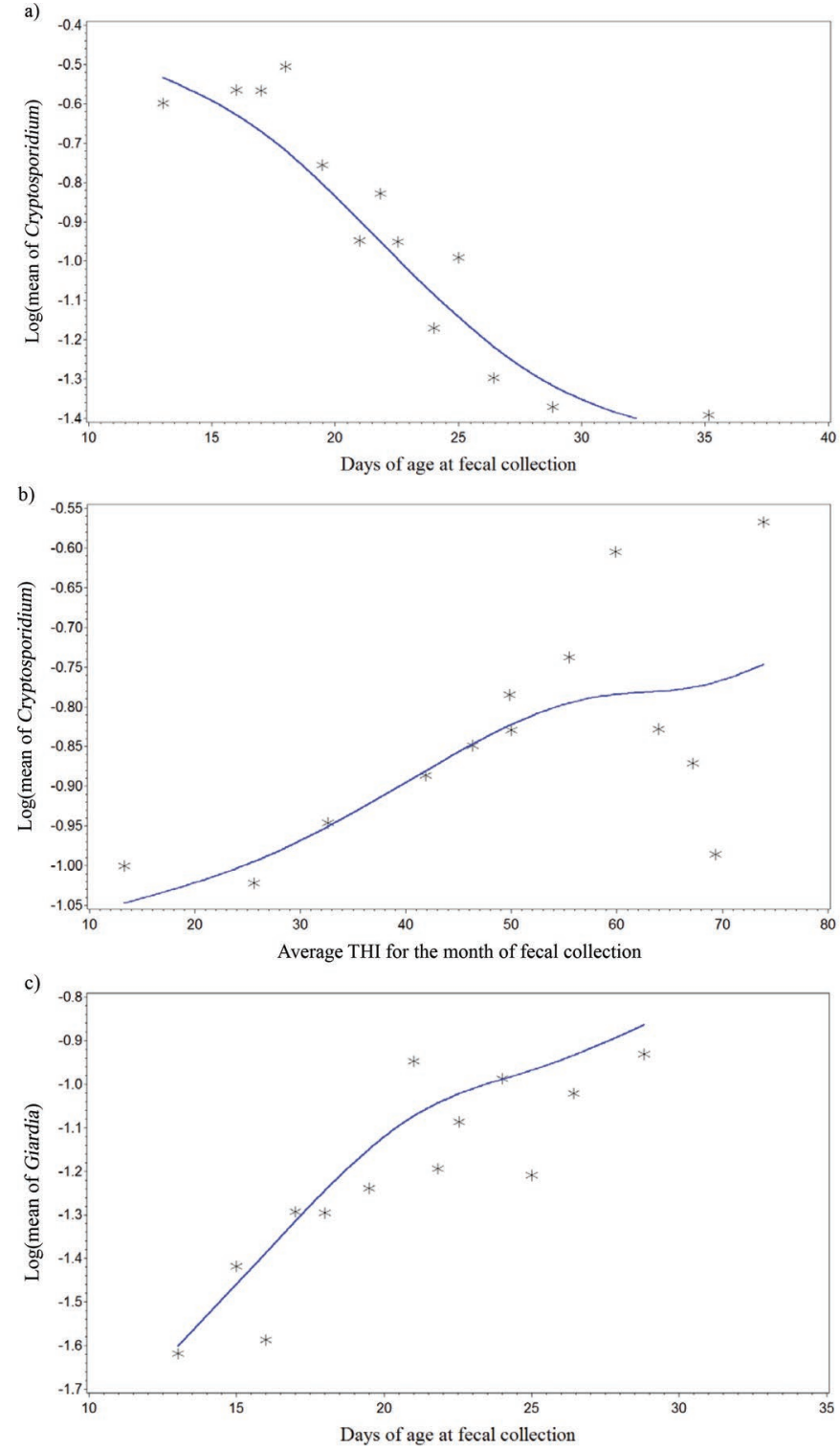

\section{DISCUSSION}

Cryptosporidium oocysts and Giardia cysts were detected in 43.1 and $30.5 \%$ of the 2,249 fecal specimens examined by immunofluorescence assay. The prevalence found in this study for Cryptosporidium and Giardia is similar to that found in previous studies in preweaned calves in the United States using the same detection method (Santín et al., 2004, 2008, 2009; Trout et al., 2004). In 2 studies in preweaned dairy calves from 7
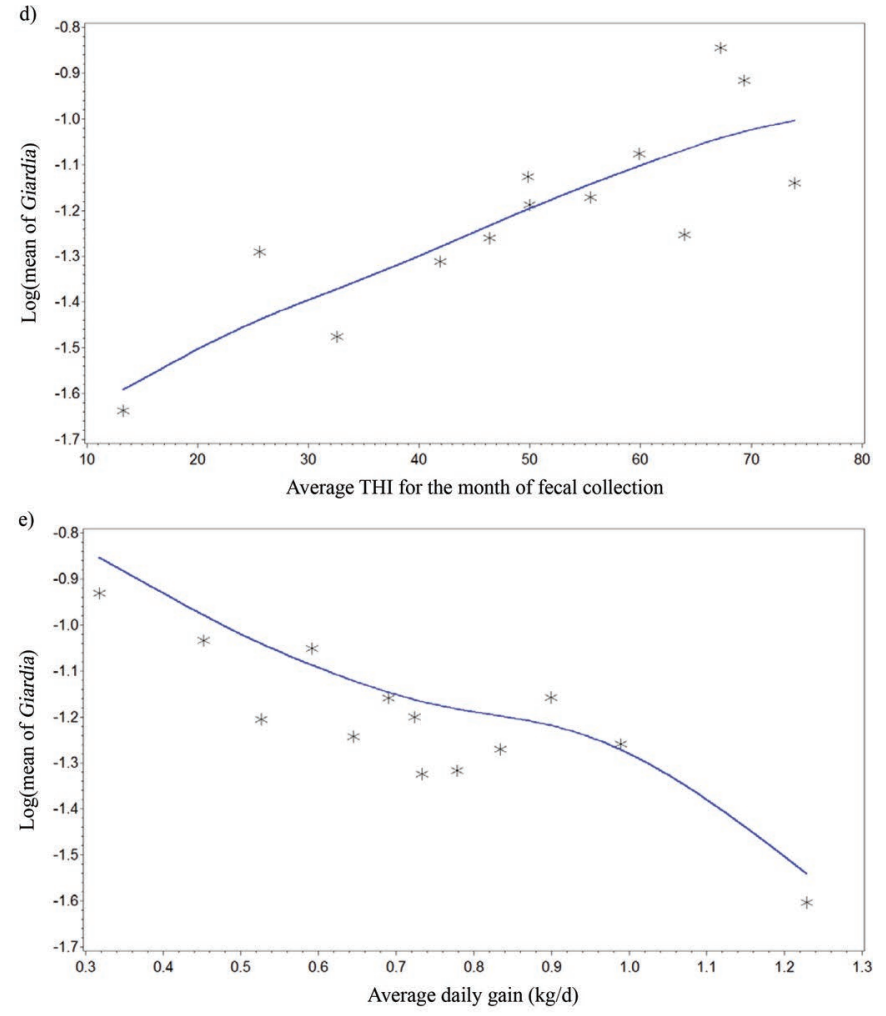

Figure 6. Model of Cryptosporidium and Giardia risk by days of age at fecal collection (a, c), average temperature-humidity index (THI) during the month of fecal collection (b,d), and ADG during the preweaning period (e). The THI accounts for the effects of temperature and relative humidity $(\mathrm{RH})$ and the equation uses the dry bulb temperature $\left(\mathrm{T},{ }^{\circ} \mathrm{F}\right)$. The equation used for this analysis was $\mathrm{THI}=\mathrm{T}-[0.55-(0.55$ $\times \mathrm{RH} / 100)] \times(\mathrm{T}-58)$. Color version available online. 
URIE ET AL.
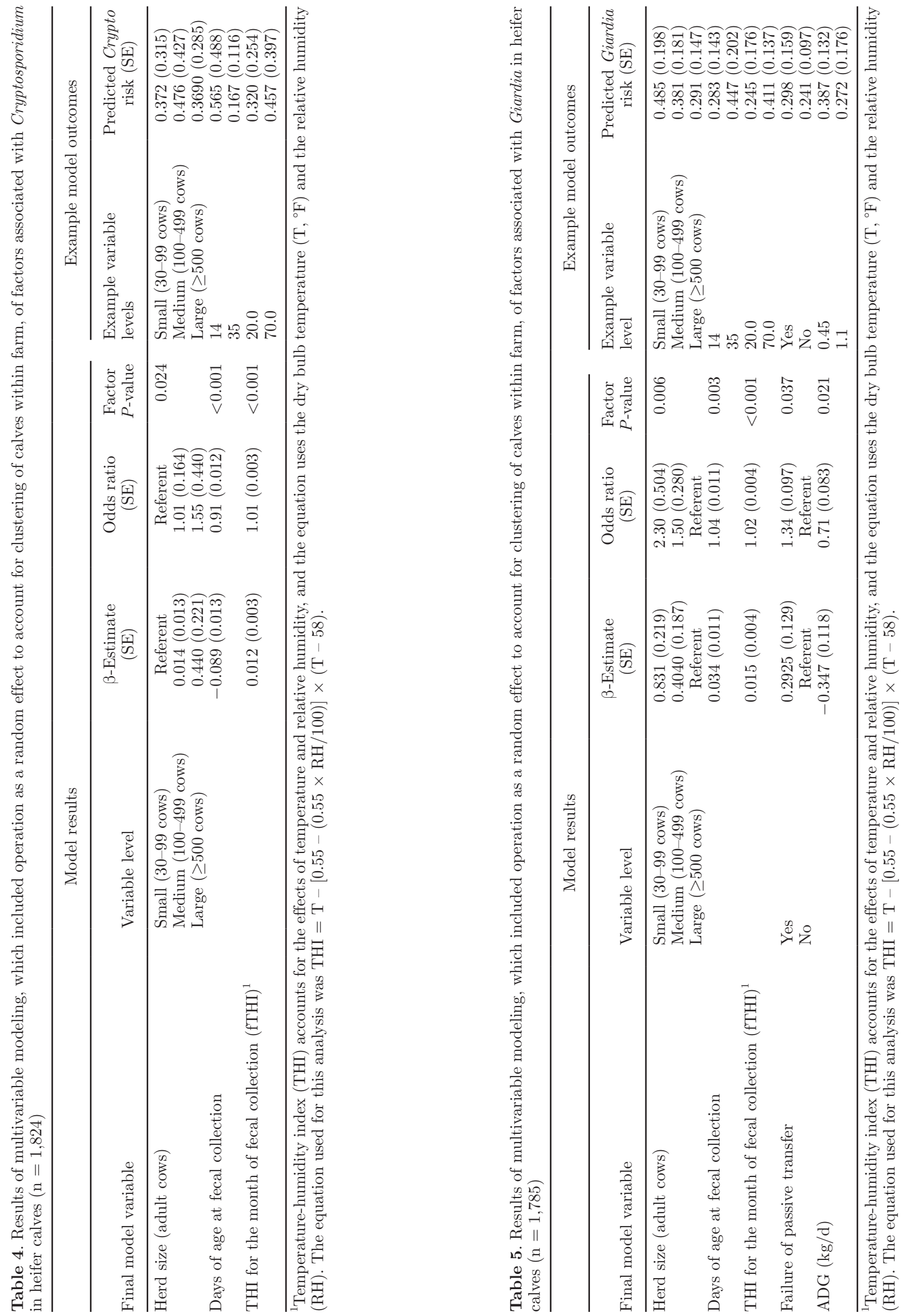
eastern US states, prevalences of 50.3 and $44 \%$ were reported for Cryptosporidium and Giardia, respectively (Santín et al., 2004; Trout et al., 2004). In studies that examined preweaned dairy calves from a farm in Maryland, a prevalence of $35.8 \%$ for Cryptosporidium and a prevalence of $60.8 \%$ for Giardia were reported (Santín et al., 2008, 2009). In a similar study in Ohio, using also immunofluorescence assay, a prevalence of similar prevalence was observed in calves 1 to 8 wk of age for Cryptosporidium (43.3\%), and a higher prevalence was observed for Giardia (70\%; Xiao and Herd, 1994). However, the prevalence of infection in cross-sectional studies likely underestimates true prevalence because only one fecal specimen was collected per calf. If that specimen were identified as negative during a period when the calf was experiencing intermittent oocyst/ cyst excretion, the calf would be considered negative. A cumulative prevalence of $100 \%$ has been reported for Cryptosporidium and Giardia dairy calves in longitudinal studies (Xiao and Herd, 1994; O'Handley et al., 1999; Santín et al., 2008, 2009).

Given that the majority of small and mediumsized operations in the data set were located in the East region, we suspected that confounding between herd size and region was possible; however, this was ruled out by evaluation of variance inflation factors. Therefore, the association between herd size and prevalence of Cryptosporidium and Giardia is likely due to management factors that vary based on operation size. Although no publications speculate regarding the association between protozoa and herd size, this association was also reported in the 1992 USDA National Dairy Heifer Evaluation Project (USDA, 1992). One possible hypothesis to explain why Cryptosporidium was more prevalent on large operations is that large operations have a greater number of calves throughout the year. Therefore, these large operations may have more calves shedding Cryptosporidium at approximately 2 wk of age, while simultaneously having more calves susceptible to Cryptosporidium. Giardia was more common on small and medium-sized operations. This may be due to smaller operations housing preweaned calves in proximity to older weaned calves, or differences in cleaning and disinfecting protocols on small and medium operations than on large operations. Older asymptomatic calves, which are more likely to have been exposed to Giardia, may be an infection source for preweaned calves on small and medium operations.

Similarly, age at fecal collection was associated with both Cryptosporidium and Giardia detection. Younger calves were at a higher risk of having a Cryptosporidium-positive fecal result. A longitudinal study of cryptosporidiosis in dairy cattle from birth to $2 \mathrm{yr}$ of age found similar results, with the highest prevalence of infection at 2 wk of age (Santín et al., 2008). Given the lifecycle of Cryptosporidium, it is likely that calves become infected via direct contamination near the time of birth, and, therefore, the peak shedding of oocysts in feces is seen at approximately 2 wk of age (Olson et al., 2004). On the other hand, older calves were at a higher risk of having a Giardia-positive fecal result. Similar results were observed in a longitudinal study of giardiasis in dairy cattle in which the number of Giardia-infected animals peaked at 4 and 5 wk of age (Santín et al., 2008). Other studies also showed that calves, both dairy and beef, greater than $30 \mathrm{~d}$ of age have a higher prevalence of shedding Giardia (Xiao, 1994; O'Handley et al., 1999; Ralston et al., 2003).

Additionally, an increase in THI for the month of fecal collection was positively correlated with both Cryptosporidium- and Giardia-positive fecal results. Several studies have illustrated that extreme temperatures, both hot and cold, can inactivate protozoal oocysts and cysts (Fayer, 1994; Fayer and Nerad, 1996; Jenkins et al., 1997, 2002; Olson et al., 1999; Herk et al., 2004). Given that very few locations in this study had extreme high temperatures, fewer Cryptosporidium- and Giardia-positive calves detected in cold temperatures are consistent with these previous studies. However, it is important to note that the amount of water in the environment may change the number of oocysts inactivated at extreme temperatures (Jenkins et al., 1997, 2002). Therefore, extreme temperatures at which oocysts are no longer active may be regionally dependent.

A calf that had failure of passive transfer (serum IgG $<10 \mathrm{~g} / \mathrm{L}$ ) was more likely to have a positive Giardia fecal result compared with calves with adequate passive transfer status. O'Handley et al. (2003) showed that antibody titers to Giardia were significantly higher in colostrum than in milk, and that antibody titers in colostrum reacted strongly with many Giardia antigens. Consequently, we might conclude that calves fed higher quality colostrum received a higher amount of Giardia antibodies and were less likely to have a positive fecal result. Although passive transfer was not significant in the Cryptosporidium model, previous studies have shown that adequate passive transfer may help minimize or eliminate Cryptosporidium infection (Lopez et al., 1988; Fayer et al., 1989; Petersen et al., 1992). Therefore, feeding high-quality colostrum and ensuring passive transfer is an important management practice to minimize protozoal infections.

Lower ADG was associated with a positive Giardia fecal result. Previous studies have shown that various livestock species, including sheep and cattle, have a decreased ADG when infected with Giardia (Ralston et al., 2003; Olson et al., 2004). As initially discussed, Giardia is known to cause chronic infection, resulting 
in prolonged diarrhea, compared with Cryptosporidium. Given this prolonged infection, it may explain why a decrease in ADG was seen in the Giardia model but not in the Cryptosporidium model.

\section{CONCLUSIONS}

Various factors play a role in the prevalence of Cryptosporidium and Giardia in preweaned dairy heifer calves. The Cryptosporidium prevalence of $43.1 \%$ and the Giardia prevalence of $30.5 \%$ were similar to those of previously reported studies, illustrating the persistence of these 2 pathogens in the dairy industry. The size of the dairy operation and the THI when calves are in the preweaning period may change the likelihood of positive Cryptosporidium or Giardia fecal results. However, ensuring adequate passive transfer will decrease the likelihood of protozoal infection. Additionally, decreasing the likelihood of protozoal infection may result in calves with a higher ADG throughout the preweaning period.

\section{ACKNOWLEDGMENTS}

We thank the 104 dairy producers and their staff for participating in the study; the federal and state animal health personnel who assisted in collecting the data; Judy Rodriguez (USDA NAHMS, Fort Collins, CO) for technical assistance in data validation and analysis; and Ken Leslie (Ontario Veterinary College, University of Guelph, Guelph, ON, Canada), Jud Heinrichs (Department of Animal Science, Pennsylvania State University, University Park, PA), Robert James (Down Home Heifer Solutions Inc., Blacksburg, VA), Dan Catherman (Strauss Feeds, Watertown, WI), Nina von Keyserlingk (Animal Welfare Program, Faculty of Land and Food Systems, University of British Columbia, Vancouver, British Columbia, Canada), and Daniel Weary (Daniel Weary (Animal Welfare Program, Faculty of Land and Food Systems, University of British Columbia, Vancouver, British Columbia, Canada) for their guidance in study design and analysis.

\section{REFERENCES}

Chester-Jones, H., and P. C. Hoffman. 2003. Calf nutrition: Raising dairy replacements. P. C. Hoffman, and R. Plourd, ed. Midwest Plan Service, Ames, IA.

de Graaf, D. C., E. Vanopdenbosch, L. M. Ortega-Mora, H. Abbassi, and J. E. Peeters. 1999. A review of the importance of cryptosporidiosis in farm animals. Int. J. Parasitol. 29:1269-1287.

Di Genova, B. M., and R. R. Tonelli. 2016. Infection strategies of intestinal parasite pathogens and host cell responses. Front. Microbiol. 7. https://doi.org/10.3389/fmicb.2016.00256.

Fayer, R. 1994. Effect of high temperature on infectivity of Cryptosporidium parvum oocysts in water. Appl. Environ. Microbiol. 60:2732-2735
Fayer, R., C. Andrews, B. L. P. Ungar, and B. Blagburn. 1989. Efficacy of hyperimmune bovine colostrum for prophylaxis of cryptosporidiosis in neonatal calves. J. Parasitol. 75:393-397. https:// doi.org $/ 10.2307 / 3282595$.

Fayer, R., and T. Nerad. 1996. Effects of low temperatures on viability of Cryptosporidium parvum oocysts. Appl. Environ. Microbiol. 62:1431-1433.

Fayer, R., M. Santin, J. M. Trout, and E. Greiner. 2006. Prevalence of species and genotypes of Cryptosporidium found in 1-2 year-old dairy cattle in the eastern United States. Vet. Parasitol. 135:105112.

Fayer, R., J. Trout, T. Graczyk, and E. Lewis. 2000. Prevalence of Cryptosporidium, Giardia and Eimeria infections in post-weaned and adult cattle on three Maryland farms. Vet. Parasitol. 93:103112. https://doi.org/10.1016/S0304-4017(00)00356-3.

Fayer, R., M. Santin, and J. M. Trout. 2007. Prevalence of Cryptosporidium species and genotypes in mature dairy cattle on farms in eastern United States compared with younger cattle from the same locations. Vet. Parasitol. 145:260-266.

Feng, Y. and L. Xiao. 2011. Zoonotic potential and molecular epidemiology of Giardia species and giardiasis. Clin. Microbiol. Rev. 24:110-140.

Geurden, T., P. Geldhof, B. Levecke, C. Martens, D. Berkvens, S. Casaert, J. Vercruysse, and E. Claerebout. 2008. Mixed Giardia duodenalis assemblage $\mathrm{A}$ and $\mathrm{E}$ infections in calves. Int. J. Parasitol. 38:259-264

Heinrichs, A. J., G. W. Rogers, and J. B. Cooper. 1992. Predicting body weight and wither height in Holstein heifers using body measurements. J. Dairy Sci. 75:3576-3581.

Herk, F. H. V., T. A. McAllister, C. L. Cockwill, N. Guselle, F. J. Larney, J. J. Miller, and M. E. Olson. 2004. Inactivation of Giardia cysts and Cryptosporidium oocysts in beef feedlot manure by thermophilic windrow composting. Compost Sci. Util. 12:235-241. https://doi.org/10.1080/1065657X.2004.10702188.

Huetink, R. E. C., J. W. B. van der Giessen, J. P. T. M. Noordhuizen, and H. W. Ploeger. 2001. Epidemiology of Cryptosporidium spp. and Giardia duodenalis on a dairy farm. Vet. Parasitol. 102:53-67. https://doi.org/10.1016/S0304-4017(01)00514-3.

Jenkins, M. B., L. J. Anguish, D. D. Bowman, M. J. Walker, and W C. Ghiorse. 1997. Assessment of a dye permeability assay for determination of inactivation rates of Cryptosporidium parvum oocysts. Appl. Environ. Microbiol. 63:3844-3850.

Jenkins, M. B., D. D. Bowman, E. A. Fogarty, and W. C. Ghiorse. 2002 Cryptosporidium parvum oocyst inactivation in three soil types at various temperatures and water potentials. Soil Biol. Biochem. 34:1101-1109. https://doi.org/10.1016/S0038-0717(02)00046-9.

Langkjær, R. B., H. Vigre, H. L. Enemark, and C. Maddox-Hyttel 2007. Molecular and phylogenetic characterization of Cryptosporidium and Giardia from pigs and cattle in Demark. Parasitology 134:339-350.

Lopez, J. W., S. D. Allen, J. Mitchell, and M. Quinn. 1988. Rotavirus and Cryptosporidium shedding in dairy calf feces and its relationship to colostrum immune transfer. J. Dairy Sci. 71:1288-1294. https://doi.org/10.3168/jds.S0022-0302(88)79685-X.

Monis, P. T., P. T. Andrews, G. Mayrhofer, and P. L. Ey. 2003. Genetic diversity within the morphological species Giardia intestinalis and its relationship to host origin. Infect. Genet. Evol. 3:29-38.

NOAA. 2016. Quality controlled local climatological data (QCLCD) Accessed Mar. 1, 2016. https://www.ncdc.noaa.gov/data-access/ land-based-station-data/land-based-datasets/quality-controlled -local-climatological-data-qclcd.

O'Handley, R. M., H. Ceri, C. Anette, and M. E. Olson. 2003. Passive immunity and serological immune response in dairy calves associated with natural Giardia duodenalis infections. Vet. Parasitol. 113:89-98. https://doi.org/10.1016/S0304-4017(03)00059-1.

O'Handley, R. M., C. Cockwill, T. A. McAllister, M. Jelinski, D. W Morck, and M. E. Olson. 1999. Duration of naturally acquired giardiosis and cryptosporidiosis in dairy calves and their association with diarrhea. J. Am. Vet. Med. Assoc. 214:391-396.

Olson, M. E. 2004. Health management: Giardiasis and cryptosporidiosis. Trends Parasitol. 20:185-191. 
Olson, M. E., J. Goh, M. Phillips, N. Guselle, T. A. Mc, and T. A. Allister. 1999. Giardia cyst and Cryptosporidium oocyst survival in water, soil, and cattle feces. J. Environ. Qual. 28:1991-1996. https://doi.org/10.2134/jeq1999.00472425002800060040x.

Olson, M. E., R. M. O'Handley, B. J. Ralston, T. A. McAllister, and R. C. Andrew Thompson. 2004. Update on Cryptosporidium and Giardia infections in cattle. Trends Parasitol. 20:185-191. https:// doi.org/10.1016/j.pt.2004.01.015.

Petersen, C., J. Gut, P. S. Doyle, J. H. Crabb, R. G. Nelson, and J. H. Leech. 1992. Characterization of a > 900,000-M(r) Cryptosporidium parvum sporozoite glycoprotein recognized by protective hyperimmune bovine colostral immunoglobulin. Infect. Immun. 60:5132-5138.

Ralston, B. J., T. A. McAllister, and M. E. Olson. 2003. Prevalence and infection pattern of naturally acquired giardiasis and cryptosporidiosis in range beef calves and their dams. Vet. Parasitol. 114:113-122. https://doi.org/10.1016/S0304-4017(03)00134-1.

Santín, M. 2013. Clinical and subclinical infections with Cryptosporidium in animals. N. Z. Vet. J. 61:1-10. https://doi.org/10.1080/ 00480169.2012 .731681

Santín, M., J. M. Trout, and R. Fayer. 2008. A longitudinal study of cryptosporidiosis in dairy cattle from birth to 2 years of age. Vet. Parasitol. 155:15-23. https://doi.org/10.1016/j.vetpar.2008 .04.018.

Santín, M., J. M. Trout, and R. Fayer. 2009. A longitudinal study of Giardia duodenalis genotypes in dairy cows from birth to 2 years of age. Vet. Parasitol. 162:40-45.

Santín, M., J. M. Trout, L. Xiao, L. Zhou, E. Greiner, and R. Fayer. 2004. Prevalence and age-related variation of Cryptosporidium spe- cies and genotypes in dairy calves. Vet. Parasitol. 122:103-117. https://doi.org/10.1016/j.vetpar.2004.03.020.

Thompson, H. P., J. S. Dooley, J. Kenny, M. McCoy, C. J. Lowery, J. E. Moore, and L. Xiao. 2007. Genotypes and subtypes of Cryptosporidium spp. in neonatal calves in Northern Ireland. Parasitol. Res. 100:619-624.

Thompson, R. C., and P. T. Monis. 2004. Variation in Giardia: Implications for taxonomy and epidemiology. Adv. Parasitol. 58:69-137.

Thompson, R. C. A., C. S. Palmer, and R. O'Handley. 2008. The public health and clinical significance of Giardia and Cryptosporidium in domestic animals. Vet. J. 177:18-25. https://doi.org/10.1016/j .tvjl.2007.09.022.

Trout, J. M., M. Santin, E. Greiner, and R. Fayer. 2004. Prevalence of Giardia duodenalis genotypes in pre-weaned dairy calves. Vet. Parasitol. 124:179-186.

Urie, N. J., J. E. Lombard, C. B. Shivley, C. A. Kopral, A. E. Adams, T. J. Earleywine, J. D. Olson, and F. B. Garry. 2018. Preweaned heifer management on US dairy operations: Part I. Descriptive characteristics of preweaned heifer raising practices. J. Dairy Sci. 101:9168-9184. https://doi.org/10.3168/jds.2017-14010.

USDA. 2016. National Animal Health Monitoring System (NAHMS). Accessed Mar. 29, 2016. https://www.aphis.usda.gov/animal _health/nahms.

Xiao, L. 1994. Giardia infection in farm animals. Parasitol. Today 10:436-438

Xiao, L., and R. P. Herd. 1994. Infection pattern of Cryptosporidium and Giardia in calves. Vet. Parasitol. 55:257-262. 